\title{
Therapeutic Role of Isotretinoin in the Management of Recurrent Aphthous Stomatitis (Single-Blind Controlled Therapeutic Study)
}

\author{
Khalifa E. Sharquie ${ }^{1}$, Raad M. Helmi ${ }^{2}$, Adil A. Noaimi ${ }^{1}$, Mohand A. A. Kadhom ${ }^{3}$, \\ Raafa K. Al-Hayani ${ }^{4}$ \\ ${ }^{1}$ Scientific Council of Dermatology and Venereology-Iraqi and Arab Board for Medical Specializations, \\ Department of Dermatology and Venereology, College of Medicine, University of Baghdad, Baghdad, Iraq \\ ${ }^{2}$ Department of Oral Medicine, College of Dentistry, Al-Mustansiriya University, Baghdad, Iraq \\ ${ }^{3}$ School of Dentistry, Faculty of Medical Science, University of Duhok, Duhok, Iraq \\ ${ }^{4}$ Department of Dermatology and Venereology, Baghdad Teaching Hospital, Baghdad, Iraq \\ Email: ${ }^{*}$ sharquie@ymail.com, dr raadhelmi@yahoo.com, adilnoaimi@yahoo.com, \\ dr_mohandduhuk@yahoo.com, raafahayani@yahoo.com
}

Received 20 January 2015; accepted 8 February 2015; published 11 February 2015

Copyright ( 2015 by authors and Scientific Research Publishing Inc.

This work is licensed under the Creative Commons Attribution International License (CC BY).

http://creativecommons.org/licenses/by/4.0/

(c) (i) Open Access

\section{Abstract}

Background: Recurrent aphthous ulcer (RAS) is a common oral disease where its etiopathogenesis is not well elucidated. There was no effective curative therapy for this disease. Isotretinoin has been recently used in the treatment of Behcet's disease. Objectives: To evaluate the efficacy and safety of isotretinoin in treating RAS and the long term remission of RAS. Patients and Methods: This single-blind controlled therapeutic study conducted in Department of Dermatology-Baghdad Teaching Hospital during February 2011-January 2012. Thirty patients with typical RAS were included in this work. Detailed history and full examination were done for all patients. They were given isotretinoin $20 \mathrm{mg}$ orally once daily for three months to be seen on Day 14 firstly and then monthly to be assessed using the oral clinical manifestation index (OCMI). After isotretinoin was stopped three months later, patients were given placebo therapy for another 3 months. Results: The results of 30 treated patients were as follows: 17 (56.67\%) males and $13(43.33 \%)$ females with male to female ratio was $1.3: 1$. Their ages ranged from $12-60(35.33 \pm 12.06)$ years. The OCMI before isotretinoin therapy ranged from $7-17(13.13 \pm 2.55)$, while after therapy the mean started to decline to a lower level within the first 14 days $(P=0.103)$, and continued to decline significantly until the end of the first month of therapy $(P=0.023)$. Then the OCMI declined very significantly until the end of fourth month of therapy $(P<0.001)$. After that the mean started to

${ }^{*}$ Corresponding author.

How to cite this paper: Sharquie, K.E., Helmi, R.M., Noaimi, A.A., Kadhom, M.A.A. and Al-Hayani, R.K. (2015) Therapeutic Role of Isotretinoin in the Management of Recurrent Aphthous Stomatitis (Single-Blind Controlled Therapeutic Study). Journal of Cosmetics, Dermatological Sciences and Applications, 5, 15-21. http://dx.doi.org/10.4236/jcdsa.2015.51003 
increase until the end of the 5 months (with placebo) but it remained statistically significant compared with the baseline of mean of OCMI before treatment $(P=0.046)$. Then it continued to increase to become not significant at the end of 6 months of therapy $(P=0.107)$. Conclusion: Isotretinoin is an effective therapeutic and prophylactic promising remedy in treatment of RAS.

\section{Keywords}

\section{Recurrent Aphthous Stomatitis, Isotretinoin, Iraq}

\section{Introduction}

Recurrent aphthous stomatitis (RAS) is a common oral problem that is encountered in a round $(10 \%-25 \%$ of the population [1]. There are many varieties of RAS like minor, major and herpetiform. Minor ulcers (80\%) are less than one centimeter in diameter, usually heal within 2 weeks, and don't leave scars. Major ulcers (10\%) usually one centimeter or more in diameter, take more than minor ulcers to heal, and may leave scars, while Herpetiform ulcers (10\%) are clusters of dozens of smaller ulcers [2].

The etiology of this disease is not well elucidated [3], but there are many factors which are implicated in the etiopathogenesis like infection as herpes [4], Streptococcus sanguis [5] and cytomegalovirus infection [6] [7]. Other factors include immunological [8]-[11] genetics nutritional deficiency like vitamin B12 and folate deficiencies [11], trauma gastrointestinal diseases [1], hematological deficiencies [12]-[14], hormonal factors and allergies to food [1].

RAS in many cases is mild that does not need therapy but still there are other cases which are severe enough to interfere with life activities and need medical interference. Accordingly, there are many topical and systemic therapies that have been used like chlorhexidine [15], lidocainesolution [16], sucralfate suspension [16], topical honey [17], 5\% lactic acid [18], nigella sativa [19], novel dexamucobasemyrtle [20], myrtle [21], colchicines, pentoxifylline [22], steroids [1] [16] thalidomide [23], BCG vaccine [24], and Etanercept [25] are used to control the symptoms. Recently an Iraqi study showed that oral zinc sulfate had an effective therapeutic and prophylactic role in management of RAS [26].

Isotretinoin is a synthetic vitamin A derivative that has been widely used to treat many dermatological diseases like acne vulgaris, ichthyosis and Darier's disease [27] through its multiple effects like increasing turnover and differentiation of epithelial cells, immunomodulator action, anti-inflammatory effect [28], inhibition of Toll like receptors 2 (TLR2) [29], and antiestrogen effect [30] Most recently, Isotretinoin had been used in treatment of Behcet's disease and was found to be effective in all the mucocutaneous manifestations including pathergy test [31].

So, the aim of the present work is to evaluate the effectiveness of isotretinoin in the treatment of RAS.

\section{Patients and Methods}

This single-blind controlled therapeutic study in which thirty patients with RAS who attended who attended Behcet's disease clinic Department of Dermatology-Baghdad Teaching Hospital, Medical City; Baghdad; Iraq; were enrolled in this work during the period February 2011-January 2012.

Detailed history was taken regarding: age, gender, occupation. History of the disease, recurrence rate, duration, symptoms associated with the ulceration, interference with the swallowing, drinking or eating and aggravating factors including food type, stress and trauma were evaluated. Also, the search about their general health, previous medical history, drug history, cigarette smoking and history of the same condition or other illness in the family were carried out. All patients were subjected to full examination detecting the shape, size, number and site of the lesions.

Investigations were done for all patients like Pathergy test using 24 gauge needle, HLA typing for HLAB51, B5 and HLAB27, complete blood picture, ESR, CRP, renal function test, liver function test to exclude Behcet's disease and other internal causes of oral ulcerations. All patients were examined by ophthalmologists in the same hospital to exclude findings suggestive for Behcet's disease.

The diagnosis of RAS was based on history, clinical examination and exclusion of other causes of oral ulceration. 
Inclusion criteria were patients stopped their treatment three months before the start of the study, most cases had at least one attack per month.

Also, patients were selected only those who we trust their follow up during the course of therapy. While exclusion criteria were pregnant and nursing mothers, patients with lipid problems and cardiovascular diseases.

Formal consent was taken from each patient after full explanation about: the goal of the present study before using the remedy, the nature of the disease, course its complications, the methods of treatment, duration, cost, side effects of therapies and duration of follow up, prognosis. After full explanation regarding isotretinoin including: method of application, duration of therapy, side effects and follow up concentrating on documentation of any apparent oral ulceration, its size, location, number and associated symptoms. Patients were instructed not to stop study treatment during the study, and to consult for any cutaneous or systemic side effects that might develop. Also, the ethical approval was performed by the scientific committee of the Scientific Council of Dermatology \& Venereology Iraqi Board for Medical Specializations.

Also, because of its teratogenic effect, this drug should not be used in ladies should not become pregnant for 2 months after stopping it. Patients were instructed to use isotretinoin capsules (Retane capsules from Asia Company, Syria) orally once daily for three months to be seen on day fourteen first and then on each month to be assessed by the oral clinical manifestation index (OCMI) which is the summation of multiple scoring numbers of the clinical status of the conditions of RAS (Table 1). Then, isotretinoin capsules were stopped and placebo therapy in a form of glucose capsules was given for further 3 months.

Table 1. Oral clinical manifestation index (OCMI) type score.

\begin{tabular}{|c|c|}
\hline Type & Score \\
\hline Minor ulcer & 1 \\
\hline Major ulcer & 2 \\
\hline Herpetiform ulcer & 3 \\
\hline \multicolumn{2}{|l|}{ Number of ulcers/attack } \\
\hline $1-3$ & 1 \\
\hline $4-6$ & 2 \\
\hline $7-9$ & 3 \\
\hline $9-12$ & 4 \\
\hline More than 12 & 5 \\
\hline \multicolumn{2}{|l|}{ Duration of the attack } \\
\hline 1 - 4 days & 1 \\
\hline 5 - 8 days & 2 \\
\hline 9 - 12 days & 3 \\
\hline More than 12 days & 4 \\
\hline \multicolumn{2}{|l|}{ Frequency (attack/date) } \\
\hline 0 - 2 weeks & 5 \\
\hline 3 - 4 weeks & 4 \\
\hline 5 - 6 weeks & 3 \\
\hline 7 - 8 weeks & 2 \\
\hline More than 8 weeks & 1 \\
\hline \multicolumn{2}{|l|}{ Associated symptoms } \\
\hline Uncomfortable & 1 \\
\hline Painful but not interfere with eating or swallowing & 2 \\
\hline Interfere with solid feeding & 3 \\
\hline Interfere with liquid feeding & 4 \\
\hline
\end{tabular}


The data were analyzed, and the student test was used to compare the means of OCMI before therapy and at Day 14, one month, two months, three months, four months, five months and six months of therapy.

The response was estimated by calculating the reduction in the means of OCMI at Day 14, one month, two months, three months, four months, five months and six months of therapy from the baseline of mean of OCMI before treatment. $\mathrm{P}$ value of less than 0.05 was considered to be statistically significant.

\section{Results}

Thirty patients were included in this study; 17 males (56.7\%) and 13 females (43.3\%), with male to female ratio was 1.3:1. Their ages ranged between 12 - 60 years with a mean \pm SD of $35.4 \pm 11.97872$ years.

OCMI before treatment was ranged from $7-17$ with mean \pm SD of $(13.133 \pm 2.556)$. OCMI was started to decrease after two weeks of therapy but the decrease was statistically not significant $(\mathrm{P}>0.05)$. After one month, this decrease was statistically significant $(P=0.023)$ and continued to decrease. At the end of three months, the decrease was statistically highly significant $(\mathrm{P}<0.001)$. Although Isotretinoin was stopped, the effect continued till the end of fifth month and was also statistically significant $(P=0.046)$. Also at the end of the six months there was a slight continued effect although was not statistically significant $(\mathrm{P}>0.05)$.

After placebo treatment, patients showed no improvement but the effect of Isotretinoin continued with gradual increase in the mean of OCMI until reached a level which was almost comparable to baseline data (Table 2).

\section{Discussion}

RAS is a major health problem but its etiopathogenesis is not well elucidated [3].

There are many therapies have been used to treat RAS but none of them is curable [29] and there is a high relapse rate when these therapies are stopped. Still some patients might get remission either as a result of therapy or spontaneously [26].

Dapsone and oral zinc sulfate have been used successfully in treatment of RAS through double blind therapeutic study and both of them showed effective therapeutic and prophylactic actions in controlling the disease [26].

The present work using oral Isotretinoin showed a new effective therapy in controlling RAS. The effect of this drug started after 14 days and became statistically significant after one month $(\mathrm{P}=0.023)$ then the OCMI continued to decrease and became highly significant at the end of three months of therapy $(\mathrm{P}<0.001)$. When the treatment was stopped and placebo started at the end of three months, the effectiveness of Isotretinoin continued and remained highly significant $(\mathrm{P}<0.001)$ at the end of four months and significant at the end of fifth month $(\mathrm{P}$ $=0.046)$.

This could be explained as retinoids in general are stored in fatty tissue for longer time after stopping the therapy [32]-[34]. Acitretin could be also tried in treatment of oral aphthosis and probably might has a similar effect to isotretinoin and preferably might have longer prophylactic effect as it may stay in the body for about 2 years after stopping therapy [35].

These results are closely similar and comparable to the effectiveness of isotretinoin in controlling the oral manifestations in patient with Behcet's disease [31].

Accordingly, Isotretinoin had a prophylactic action in addition to its therapeutic effect. These results are very comparable to the results of dapsone and oral zinc sulfate although isotretinoin was less effective than zinc sulfate and dapsone (Table 3).

Table 2. Effects of the drug on OCMI.

\begin{tabular}{|c|c|c|c|c|c|c|c|c|}
\hline & \multicolumn{5}{|c|}{ Isotretinoin therapy } & \multicolumn{3}{|c|}{ Placebo therapy } \\
\hline & $\begin{array}{l}\text { Before } \\
\text { therapy }\end{array}$ & Day 14 & One month & $\begin{array}{c}\text { Two } \\
\text { months }\end{array}$ & $\begin{array}{l}\text { Three } \\
\text { months }\end{array}$ & $\begin{array}{c}\text { Four } \\
\text { months }\end{array}$ & $\begin{array}{c}\text { Five } \\
\text { months }\end{array}$ & Six months \\
\hline Mean & 13.133 & 10.567 & 7.6 & 5.5667 & 4.0667 & 5.9333 & 8.2 & 10.667 \\
\hline $\mathrm{SD}$ & 2.556 & 3.9277 & 4.9522 & 5.3219 & 4.2421 & 4.7119 & 4.3263 & 3.8714 \\
\hline P-value & & $\begin{array}{c}0.103 \\
\text { NS }\end{array}$ & $\begin{array}{c}0.023 \\
\mathrm{~S}\end{array}$ & $\begin{array}{c}\mathrm{P}<0.001 \\
\text { HS }\end{array}$ & $\begin{array}{c}\mathrm{P}<0.001 \\
\mathrm{HS}\end{array}$ & $\begin{array}{c}\mathrm{P}<0.001 \\
\text { HS }\end{array}$ & $\begin{array}{c}0.046 \\
S\end{array}$ & $\begin{array}{c}0.107 \\
\text { NS }\end{array}$ \\
\hline
\end{tabular}


Table 3. Comparison between effects of zinc sulfate, dapsone and isotretinoin OCMI score.

\begin{tabular}{cccccccc}
\hline $\begin{array}{c}\text { OCMI } \\
\text { score }\end{array}$ & Zinc sulfate & $\begin{array}{c}\text { Reduction } \\
\text { in mean }\end{array}$ & Dapsone & $\begin{array}{c}\text { Reduction in } \\
\text { mean }\end{array}$ & Isotretinoin & $\begin{array}{c}\text { Reduction in } \\
\text { mean }\end{array}$ & P-value \\
\hline At day 0 & 11.93 & & 10.87 & & 13.133 & & \\
At 2 weeks & 6.07 & 5.86 & 3.73 & 7.14 & 10.567 & 2.566 & $\begin{array}{c}0.034 \\
\text { S } \\
0.039 \\
\text { S }\end{array}$ \\
At one month & 1.73 & 10.2 & 4.40 & 6.47 & 7.6 & 5.533 & 0.089 \\
At 2 months & 2.80 & 9.13 & 4.27 & 6.6 & 5.5667 & 7.566 & NS \\
At 3 months & 0.93 & 11 & 2.80 & 8.07 & 4.0667 & 9.066 & 0.048 \\
\hline
\end{tabular}

The mechanism of action of isotretinoin in controlling RAS is difficult to be explained but it might work through its multiple actions like increasing differentiation of epithelial cells, antiinflammatory effect, immunomodulator effect [28], Tolllike receptors 2 (TLR2) [29] and antiestrogenic effect [30].

The present study showed that isotretinoin is an effective therapy but unfortunately it might be associated with side effects like dryness of the lip, mucosa, skin and eye [32]. Also because of its teratogenic effect [32], this drug should not be used in pregnant and ladies should not become pregnant for 2 months after stopping it. But when the patient gets better, the dose of therapy could be minimized to reduce these side effects. Hence isotretinoin could be used either alone in cases failed to respond to other therapies or as a combined therapy with others like dapsone and zinc sulfate especially in difficult refractory cases.

\section{Conclusion}

To the best of our knowledge, this is the first study that has been carried out using isotretinoin in treatment of RAS. Isotretinoin is an effective new therapy for RAS either alone in cases failed to respond to other therapies or as a combined therapy with other drugs. Other retinoids like acitretin will be tried in management of oral aphthosis and Behcet disease by further studies which will be published.

\section{Disclosure}

This study was an independent study and not funded by any drug companies.

\section{References}

[1] Cawson, R.A., Odell, E.W. and Porter, S.R. (2002) Cawson's Essentials of Oral Pathology and Oral Medicine. 7th Edition, Churchill Livingstone, New York.

[2] Natah, S.S., Konttinen, Y.T., Enattah, N.S., Ashammakhi, N., Sharkey, K.A. and Hayrinen Immonen, R. (2004) Recurrent Aphthou Ulcers Today: A Review of the Growing Knowledge. International Journal of Oral and Maxillofacial Surgery, 33, 221-234. http://dx.doi.org/10.1006/ijom.2002.0446

[3] Rivera Hidalgo, F., Shulman, J.D. and Beach, M.M. (2004) The Association of Tobacco and Other Factors with Recurrent Aphthous Stomatitis in an US Adult Population. Oral Diseases, 10, 335-345. http://dx.doi.org/10.1111/j.1601-0825.2004.01049.x

[4] Katz, J., Chaushu, G. and Peretz, B. (2001) Recurrent Oral Ulcerations Associated with Recurrent Herpes LabialisTwo Distinct Entities? Community Dentistry and Oral Epidemiology, 29, 260-263. http://dx.doi.org/10.1034/j.1600-0528.2001.290404.x

[5] Sun, A., Chia, J.S. and Chiang, C.P. (2002) Increased Proliferative Response of Peripheral Blood Mononuclear Cells and T Cells to Streptococcus mutans and Glucosyltransferase D Antigens in the Exacerbation Stage of Recurrent Aphthous Ulcerations. Journal of the Formosan Medical Association, 101, 560-566.

[6] Fawaz, A. (2003) Cytological Cytogenetic and Biochemical Analysis of Behcet's Disease and Recurrent Aphthous Stomatitis. A Thesis Submitted to the College of Dentistry University of Baghdad in Partial Fulfillment of the Requirements for the Degree of Doctor of Philosophy in Oral Medicine, 44-55.

[7] Pedersen, A. and Horsleth, A. (1993) Recurrent Aphthous Ulceration: A Possible Clinical Manifestation of Reaction of Varicella Zoster of Cytomegalovirus Infection. Journal of Oral Pathology \& Medicine, 22, 64-68. 
[8] Jurge, S., Kuffer, R., Scully, C. and Porter, S.R. (2006) Mucosal Disease Series. Number VI. Recurrent Aphthous Stomatitis. Oral Diseases, 12, 1-21. http://dx.doi.org/10.1111/j.1601-0825.2005.01143.x

[9] Buno, I.J., Huff, J.C. and Weston, W.L. (1998) Elevated Levels of Interferon Gamma, Tumor Necrosis Factor $\alpha$, Interleukin 2, 4, and 5, but Not Interleukin 10, Are Present in Recurrent Aphthous Stomatitis. Archives of Dermatology, 134, 827-831. http://dx.doi.org/10.1001/archderm.134.7.827

[10] Bazrafshani, M.R., Hajeer, A.H., Ollier, W.E. and Thornhill, M.H. (2002) IL1B and IL6 Gene Polymorphisms Encode Significant Risk for the Development of Recurrent Aphthous Stomatitis (RAS). Genes \& Immunity, 3, 302-305.

[11] Kozlak, S.T., Walsh, S.J. and Lalla, R.V. (2010) Reduced Dietary Intake of Vitamin B12 and Folate in Patients with Recurrent Aphthous Stomatitis. Journal of Oral Pathology \& Medicine, 39, 420-423.

[12] Jacobson, J.M., Greenspan, J.S., Spritzler, J., Ketter, N., Fahey, J.L. and Jackson, J.B. (1997) Thalidomide for the Treatment of Oral Aphthous Ulcers in Patients with Human Immunodeficiency Virus Infection. National Institutes of Allergy and Infectious Diseases AIDS Clinical Trials Group. The New England Journal of Medicine, 336, 1487-1493. http://dx.doi.org/10.1056/NEJM199705223362103

[13] Demiroglu, H. and Dunder, S. (1997) Behcet's Disease and Chronic Neutropenia. Scandinavian Journal of Rheumatology, 26, 130-132. http://dx.doi.org/10.3109/03009749709115832

[14] Burns, D.A. and Breathnach, S.M. (2004) Recurrent Aphthous Stomatitis. In: Cox, N. and Griffiths, C., Eds., Rook’s Textbook of Dermatology, Blackwell Publishing, Oxford, 43-46. http://dx.doi.org/10.1002/9780470750520

[15] Barrons, R.W. (2001) Treatment Strategies for Recurrent Oral Aphthous Ulcers. American Journal of Health-System Pharmacy, 58, 41-50.

[16] William, D.J., Timothy, G.B. and Dirk, M.E. (2006) Recurrent Aphthous Stomatitis. Andrew’s Disease of the Skin: Clinical Dermatology. 10th Edition, WB Saunders Company, Philadelphia, 810-812.

[17] Sharquie, K.E. and Najim, R.A. (2001) Honey as a New Skin Tissue Preservative. Pan Arab League of Dermatologists, 12, 49-54.

[18] Sharquie, K.E., Al Tammimi, S.M., Al Mashhadani, S., Hayani, R.K. and Al-Nuaimi, A.A. (2006) Lactic Acid 5 Percent Mouthwash Is an Effective Mode of Therapy in Treatment of Recurrent Aphthous Stomatitis. Dermatology Online Journal, 12, 2.

[19] Abdoli, S., Hadi, N., Ali, A., Waiz, M. and Hayani, R. (2004) A Comparative Study in the Effect of Nigella Sativa Oil, Eugenol and Betamethasone in the Treatment of Recurrent Oral Ulcerations. Clinical and Experimental Rheumatology Journal, 22, 120.

[20] Al Na'mah, Z.M., Carson, R. and Thanoon, I.A. (2009) Dexamucobase: A Novel Treatment for Oral Aphthous Ulceration. Quintessence International, 40, 399-404.

[21] Babaee, N., Mansourian, A., Momen Heravi, F., Moghadamnia, A. and Momen Beitollahi, J. (2010) The Efficacy of a Paste Containing Myrtus communis (Myrtle) in the Management of Recurrent Aphthous Stomatitis: A Randomized Controlled Trial. Clinical Oral Investigations, 14, 65-70. http://dx.doi.org/10.1007/s00784-009-0267-3

[22] Fontes, V., Machet, L., Huttenberger, B., Lorette, G. and Vaillant, L. (2002) Recurrent Aphthous Stomatitiis: Treatment with Colchicines. An Open Trial of 54 Cases. Annales de Dermatologie et de Venereologie, 129, 1365-1369.

[23] Scully, C. (2006) Clinical Practice. Aphthous Ulceration. The New England Journal of Medicine, 355, 165-172. http://dx.doi.org/10.1056/NEJMcp054630

[24] Sharquie, K.E. and Hayani, R.K. (2005) BCG as a New Therapeutic and Prophylactic Agent in Patients with Severe Oral Aphthosis. Clinical and Experimental Rheumatology Journal, 23, 914.

[25] Sfikakis, P.P., Markomichelakis, N., Alpsoy, E., et al. (2007) Anti-TNF Therapy in the Management of Behcet’s Disease: Review and Basis for Recommendations. Rheumatology (Oxford), 46, 736-741.

[26] Sharquie, K.E., Najim, R.A., Al Hayani, R.K., Al Nuaimi, A.A. and Maroof, D.M. (2008) The Therapeutic and Prophylactic Role of Oral Zinc Sulfate in Treatment of Recurrent Aphthous Stomatitis in Comparison with Dapsone. Saudi Medical Journal, 29, 734-738.

[27] Kontaxakis, V.P., Skourides, D., Ferentinos, P., Havaki-Kontaxaki, B.J. and Papadimitriou, G.N. (2009) Isotretinoin and Psychopathology: A Review. Annals of General Psychiatry, 8, 2. http://dx.doi.org/10.1186/1744-859X-8-2

[28] Chandraratna, R.A. (1998) Rational Design of Receptor-Selective Eretinoids. Journal of the American Academy of Dermatology, 39, 124-128.

[29] Fathy, A., Mohamed, R.W., Ismael, N.A. and El Akhras, M.A. (2009) Expression of Toll-Like Receptor 2 on Peripheral Blood Monocytes of Patients with Inflammatory and Noninflammatory Acne Vulgaris. Egyptian Journal of Immunology, 16, 127-134.

[30] Czeczuga Semeniuk, E., Anchim, T., Dziecioł, J., Dabrowska, M. and Wołczyński, S. (2004) Can Transforming Growth 
Factor-Beta1 and Retinoids Modify the Activity of Estradiol and Antiestrogens in MCF-7 Breast Cancer Cells? Acta Biochimica Polonica, 51, 733-745.

[31] Sharquie, K.E., Helmi, R.M.A., Noaimi, A.A., Al Hayani, R.K. and Khadom, M.A.A. (2013) The Therapeutic Role of Isotretinoin in the Management of Bahçet Disease: A Single-Blind, Controlled Therapeutic Study. Journal of Drugs in Dermatology, 12, e68-e73.

[32] Malvasi, A., Tinelli, A., Buia, A. and De Luca, G.F. (2009) Possible Long Term Teratogenic Effect of Isotretinoin in Pregnancy. European Review of Medical and Phamacological Sciences, 13, 393-396.

[33] Sampaio, S.P.A. and Rivitti, E.A. (2001) Dermatologia. Artes Médicas, São Paulo.

[34] Soprano, D.R. and Blaner, W.S. (1994) Plasma Delivery of Retinoic Acid to Tissues in the Rat. In: Sporn, M.B., Roberts, A.B. and Goodman, D.S., Eds., The Retinoids, Biology, Chemistry and Medicine, 2nd Edition, Raven Press, Ltd., New York, 257-282.

[35] McNamara, P.J., Jewell, R.C., Jensen, B.K., et al. (1988) Food Increases the Bioavailability of Acitretin. The Journal of Clinical Pharmacology, 28, 1051-1055. 
Scientific Research Publishing (SCIRP) is one of the largest Open Access journal publishers. It is currently publishing more than 200 open access, online, peer-reviewed journals covering a wide range of academic disciplines. SCIRP serves the worldwide academic communities and contributes to the progress and application of science with its publication.

Other selected journals from SCIRP are listed as below. Submit your manuscript to us via either submit@scirp.org or Online Submission Portal.
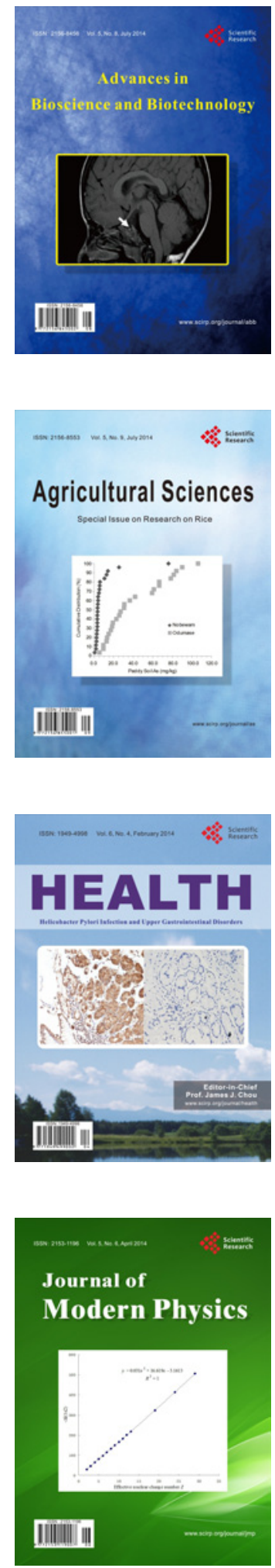
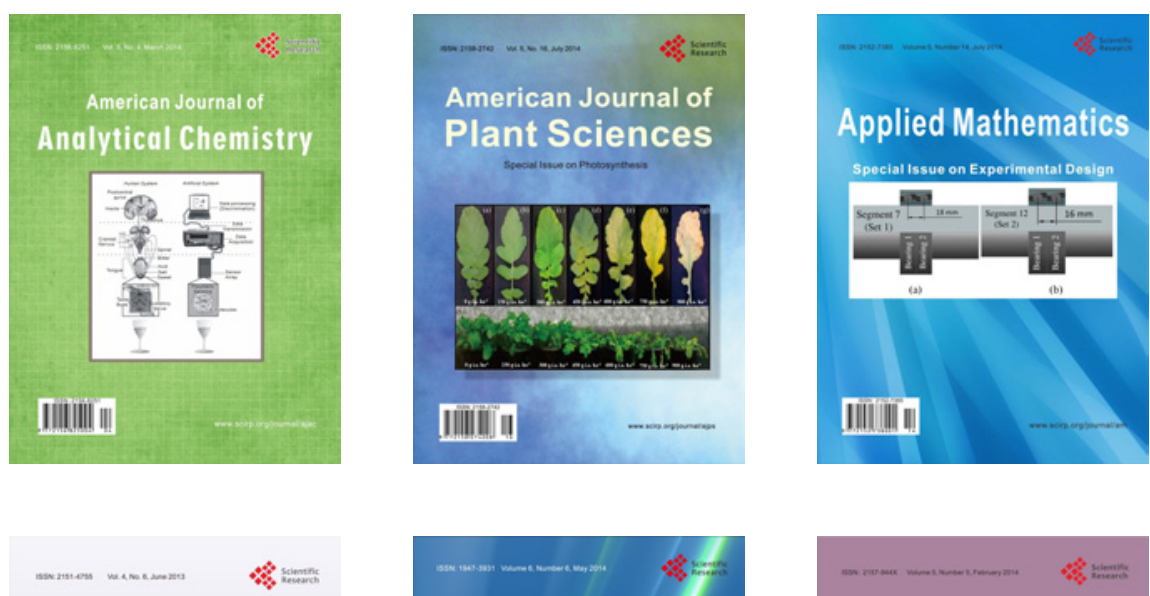

Creative Education
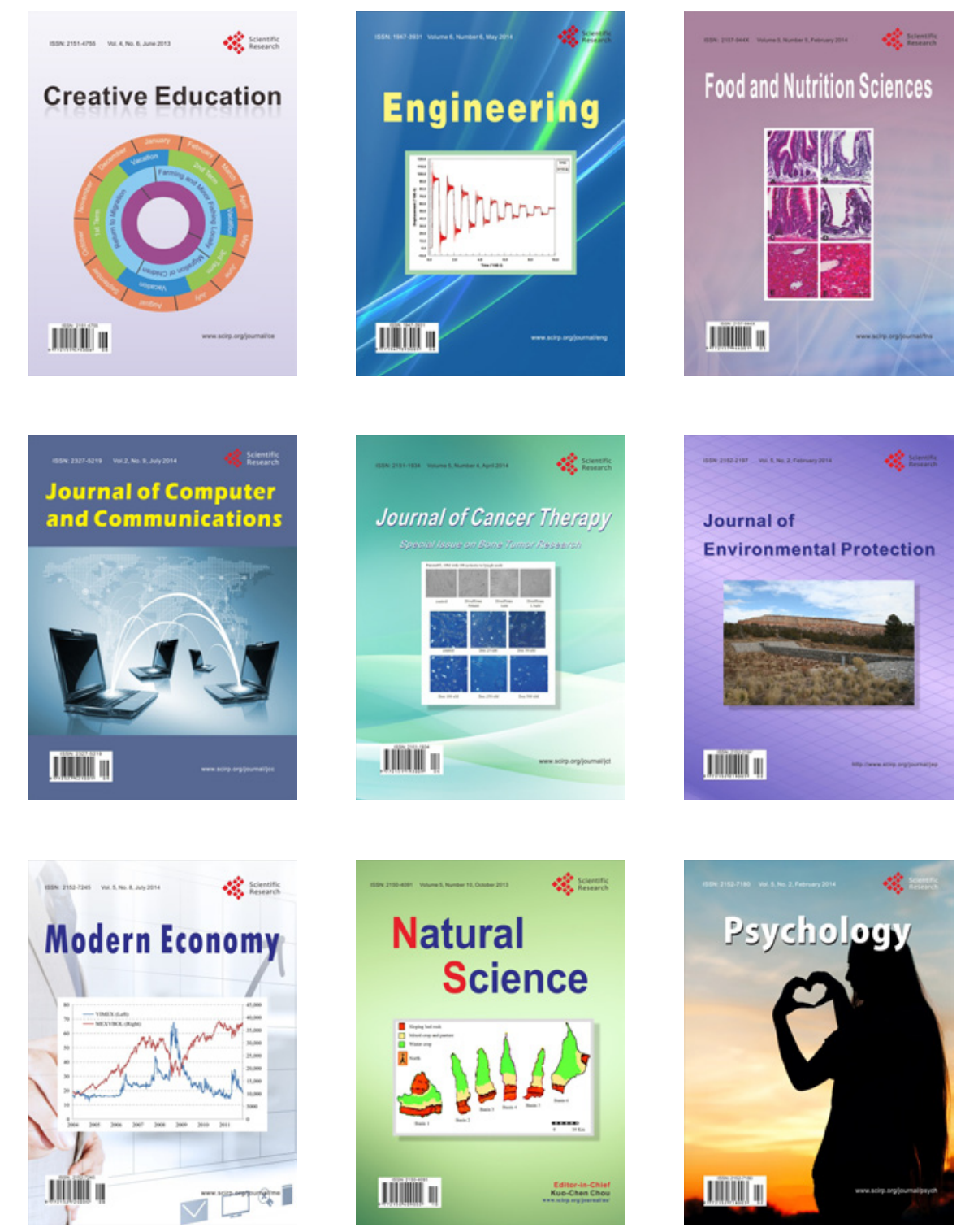